Case Report

\title{
Role of Fine Needle Aspiration in the Diagnosis of the Rare Disease of Langerhans Cell Histiocytosis in a Child
}

\author{
Seema Lale, ${ }^{1}$ Daniel Soto, ${ }^{2}$ and Patricia G. Wasserman ${ }^{3}$ \\ ${ }^{1}$ Mercy Hospital, 800 Myrtle Street, Independence, KS 67301, USA \\ ${ }^{2}$ Long Island Jewish Health System, 6 Ohio Drive, Lake Success, NY 11040, USA \\ ${ }^{3}$ Cytopathology, Columbia University Medical Center, 630 West 168th Street, New York, NY 10032, USA
}

Correspondence should be addressed to Seema Lale; seemalale@yahoo.com

Received 25 September 2013; Accepted 9 December 2013; Published 22 January 2014

Academic Editors: A. A. Ahmed and D. Tsuruta

Copyright (C) 2014 Seema Lale et al. This is an open access article distributed under the Creative Commons Attribution License, which permits unrestricted use, distribution, and reproduction in any medium, provided the original work is properly cited.

Langerhan's cell histiocytosis (LCH) results from the proliferation of immunophenotypically and functionally immature, morphologically rounded Langerhan's cells along with eosinophils, macrophages, lymphocytes, and, commonly, multinucleated giant cells. Here we report a case in a 6-year-old boy of differential diagnoses including dermatopathic lymphadenitis (DL), parasitic infection, Kimura's disease, hypersensitivity reactions, cat-scratch disease, sinus histiocytosis with massive lymphadenopathy (SHML), hyperplasic lymph nodes, and lymphoma.

\section{Introduction}

Controversy exists regarding whether the immunologic abnormalities observed in LCH are the cause of the clonal proliferation lesional Langerhan's cells [1]. The etiology of LCH is unknown. Efforts to define a viral cause have not been successful $[2,3]$.

The incidence of LCH has been estimated to be 2 to 10 cases per million children aged 15 years or younger $[4,5]$. The male to female ratio is close to one and the median age of presentation is 30 months.

The nomenclature used for $\mathrm{LCH}$ indicates the disease extent (i.e., single organ, single system, multisystem, or diffuse). Prognosis and treatment are closely linked to the extent of disease at presentation and whether high-risk organs (spleen, liver, bone marrow, and lung) are involved.

The outcome for children with LCH involving low-risk organs (skin, bones, lymph node, and pituitary gland) has always been excellent.

\section{Case Report}

A 6-year-old boy presented with a four-week history of right neck swelling. On clinical examination a $3 \times 2 \mathrm{~cm}$ right cervical enlarged lymph node was noted. The patient did not have any other lymphadenopathy. There was no significant clinical history including weight loss or fever. Skeletal survey was normal. There were no osseous lytic lesions.

PET scan was reported to be normal.

Fine needle aspiration (FNA) of the right neck lymph node was performed. Cytology smears were prepared.

\section{Materials and Methods}

Diff-Quik (Medical Chemical Corp., Torrance, CA, USA) and Papanicolaou stains (Cardinal Health, Ontario, Canada) were performed. The residual pellet, after Cytospin processing, was fixed in $10 \%$ buffered neutral formalin for cell block preparation followed by hematoxylin and eosin (H\&E) staining and ancillary studies.

Immunocytochemistry stains were performed on unstained sections of formalin fixed, paraffin embedded cell block by the standard avidin-biotin technique. The panel of antibodies used included CDla, CD68, and S 100.

\section{Results}

The cellular aspirate smears showed numerous single lying mononucleated and multinucleated histiocytes with 


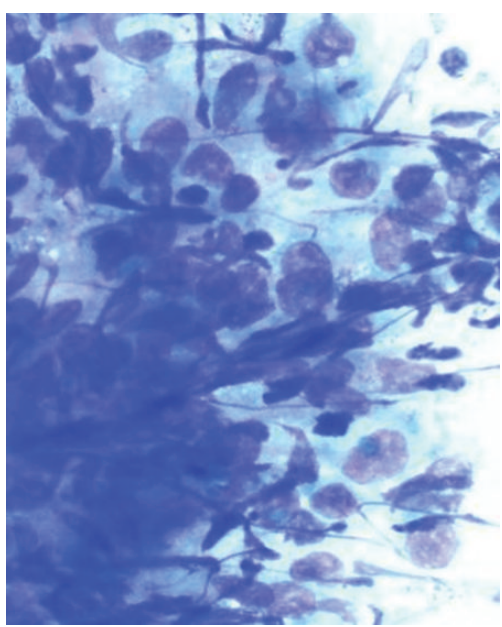

(a)

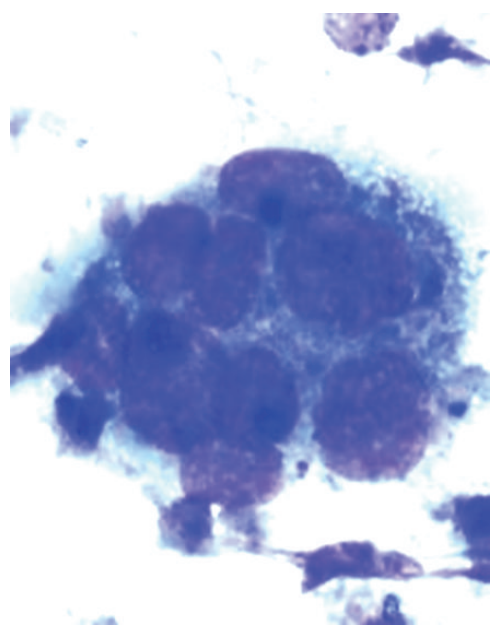

(b)

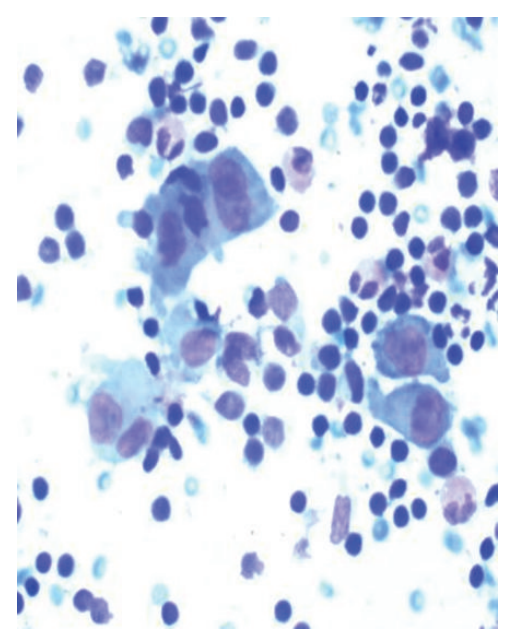

(c)

FIGURE 1: DQ-stained smears ( $\times 100$, left), (×400 middle), and, $(\times 100$ right $)$.

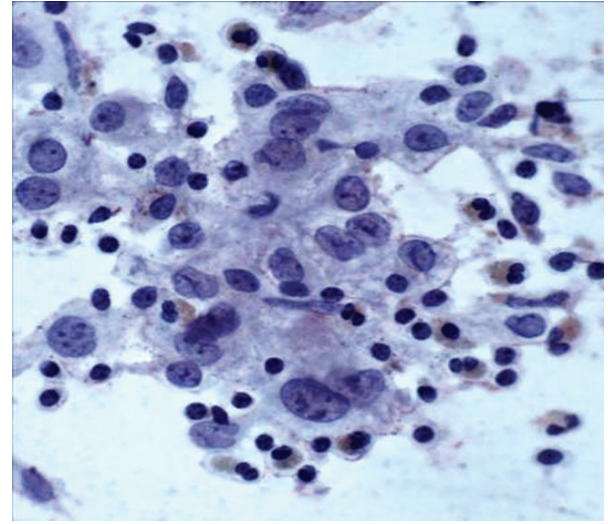

(a)

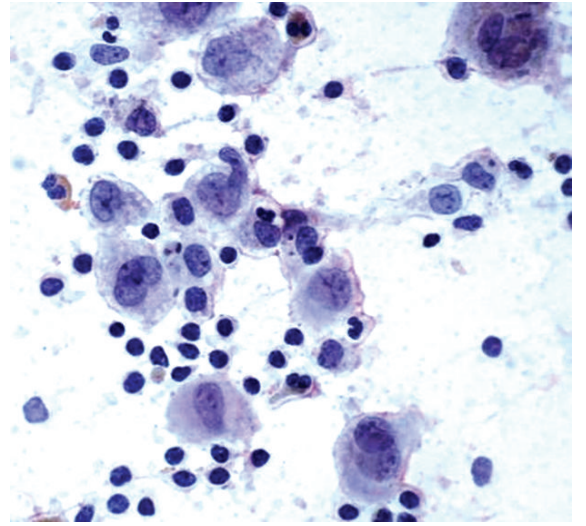

(b)

Figure 2: Pap-stained smear, $\times 200$ (left), $\times 400$ (right).

abundant vacuolated cytoplasm and grooved, folded, and indented nuclei. The background consisted of abundant eosinophils, mixed lymphoid population, and lymphohistiocytic aggregates. No significant mitotic activity was noted. In Papanicolaou stain (Figure 2), the chromatin was fine and even, nucleoli were inconspicuous, and the cytoplasm was abundant and pale staining. In DiffQuik (Figure 1), the Langerhan's cells had a plasmacytoid appearance, with eccentrically placed nuclei and abundant basophilic cytoplasm. Immunocytochemical stains were performed on the cell block and the tumor cells stained positively with CD1a, S-100 (Figure 3), and CD68. This immunoprofile was most consistent with Langerhan's cell histiocytosis.

\section{Discussion}

Langerhan's cell histiocytosis (LCH), or histiocytosis X, is a group of diseases characterized by proliferation of the
Langerhan's cell. These disorders can involve many organ systems but primarily affect the bone, skin, lymph nodes, lungs, liver and spleen, endocrine glands, and nervous system. The separation of these conditions into separate entities, Letterer-Siwe disease, Hand-Schuller-Christian disease, and eosinophilic granuloma, is of historical interest [6]. The disease affects young children from 1 to 4 years but can present from birth to the ninth decade [6]. In a large series of 124 patients, bone, lymph node, and skin lesions were the most frequently seen, but $50 \%$ of patients showed liver disease and $23 \%$ lung disease with frequent hematological disease [7]. $\mathrm{LCH}$ involving lymph nodes usually occurs in patients in the pediatric age group with known systemic disease. However, rarely, LCH can primarily involve lymph nodes without other sites of the disease.

In a series of 20 patients with Langerhan's cell histiocytosis involving lymph nodes, only 2 patients had restricted involvement of lymph nodes as in our case and all other cases were of lymph nodes from children with multisystemic disease [8]. 


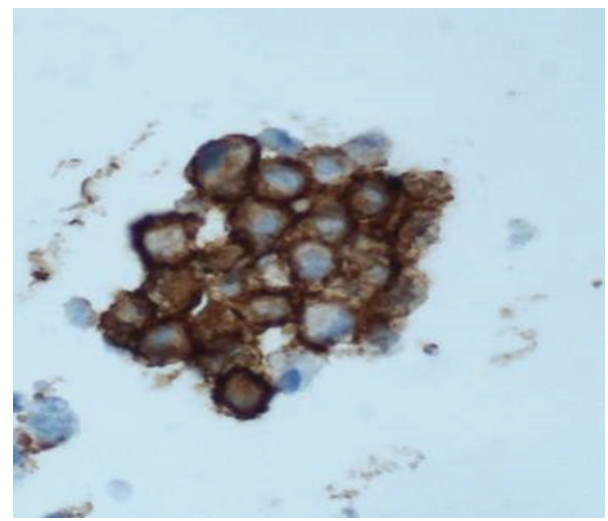

(a)

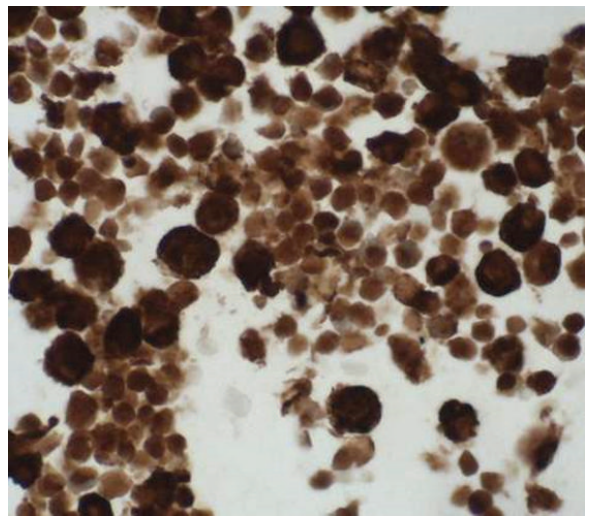

(b)

Figure 3: Ancillary studies of CDla, S-100.

The diagnosis of $\mathrm{LCH}$ in our patient was made on the basis of FNA smears of the lymph nodes. However, the differential diagnoses included conditions with localized aggregates of Langerhan's cells such as those observed in association with dermatopathic lymphadenitis (DL), parasitic infection, Kimura's disease, hypersensitivity reactions, cat-scratch disease, sinus histiocytosis with massive lymphadenopathy (SHML), and hyperplasic lymph nodes. In addition, on rare occasions, $\mathrm{LCH}$ can associate with a variety of malignant neoplasms in the same node, that is, lymphoma or metastatic neoplasms [9].

Langerhan's cells show positivity for S-100 and CD1a. Our case showed positivity for CD1a, S-100, and CD68. For localized lesions like lymph nodes, a simple, minimally invasive procedure with a low rate of complication is desirable. In view of this and the possibility of spontaneous resolution in localized disease, FNA alone could be used to confirm the diagnosis, in the correct clinical setting.

On one-year clinical followup, our patient did not have any other lymphadenopathy or bone involvement.

To conclude, the present case highlights the role of FNA in the diagnosis of the rare disease of $\mathrm{LCH}$ in a child. The cytologic features of LCH are highly characteristic to confirm the diagnosis with the help of immunocytochemistry. This can obviate the need of open biopsy and electron microscopy.

\section{Conflict of Interests}

The authors declare that there is no conflict of interests regarding the publication of this paper.

\section{References}

[1] J. D. Laman, P. J. leenen, N. E. Annels et al., "Langerhan's -cell histiocytosis 'insight into DC biology", Trends in Immunology, vol. 24, no. 4, pp. 190-196, 2003.

[2] K. McClain, H. Jin, V. Gresik, and B. Favara, "Langerhans cell histiocytosis: lack of a viral etiology," American Journal of Hematology, vol. 47, no. 1, pp. 16-20, 1994.

[3] E. Jeziorski, B. Senechal, T. J. Molina et al., "Herpes-virus infection in patients with Langerhans cell histiocytosis: a casecontrolled sero-epidemiological study, and in situ analysis," PLoS ONE, vol. 3, no. 9, Article ID e3262, 2008.

[4] J. A. Salotti, V. Nanduri, M. S. Pearce, L. Parker, R. Lynn, and K. P. Windebank, "Incidence and clinical features of Langerhans cell histiocytosis in the UK and Ireland," Archives of Disease in Childhood, vol. 94, no. 5, pp. 376-380, 2009.

[5] "A multicenter retrospective survey of Langerhan's cell histiocytosis: 348 cases observed between 1983 and 1993. The French Langerhan's cell histiocytosis study group," Archives of Disease in Childhood, vol. 75, no. 1, pp. 17-24, 1996.

[6] R. B. Odom, W. D. James, and T. G. Berger, Andrews' Disease of the Skin, W.B. Saunders Company, Philadelphia, Pa, USA, 2000.

[7] R. Rivera-Luna, G. Martinez-Guerra, E. Altamirano-Alvarez et al., "Langerhans cell histiocytosis: clinical experience with 124 patients," Pediatric Dermatology, vol. 5, no. 3, pp. 145-150, 1988.

[8] M. C. Morgenfeld and F. Schajowicz, "Solitary eosinophilic granuloma of lyumph node: five-year follow-up," Pediatrics, vol. 48, no. 2, pp. 301-305, 1971.

[9] M. P. Neumann and G. Frizzera, "The coexistence of Langerhans' cell granulomatosis and malignant lymphoma may take different forms: report of seven cases with a review of the literature," Human Pathology, vol. 17, no. 10, pp. 1060-1065, 1986. 


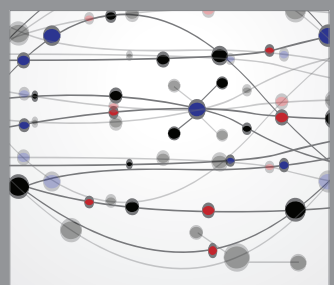

The Scientific World Journal
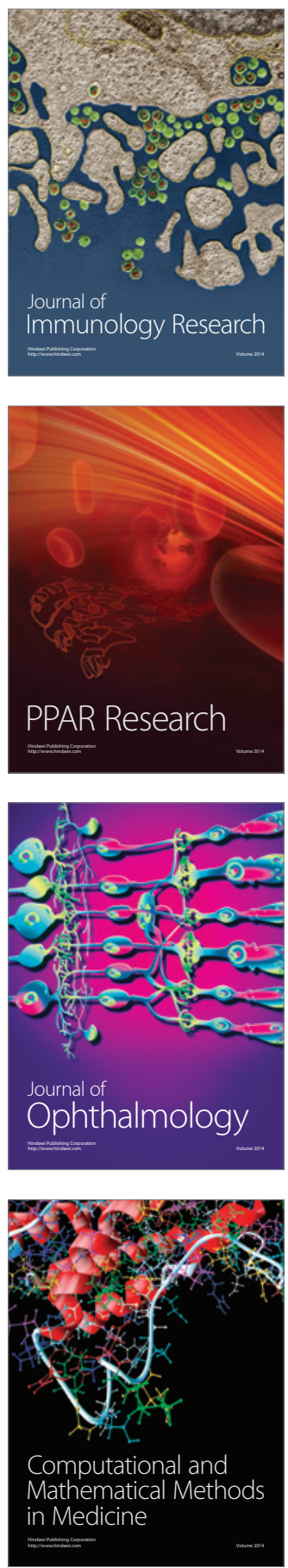

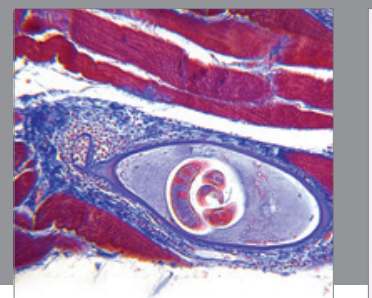

Gastroenterology

Research and Practice
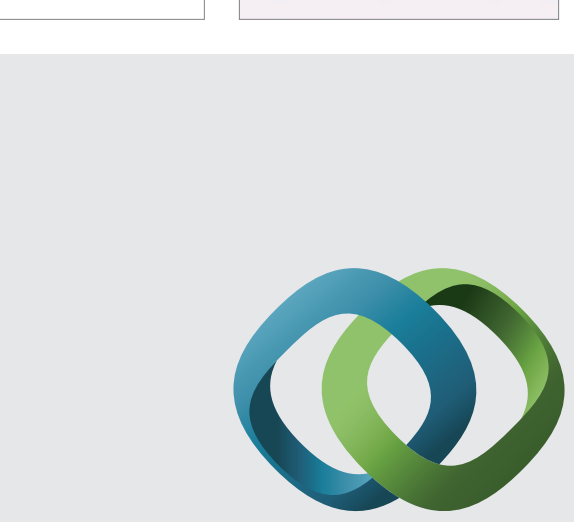

\section{Hindawi}

Submit your manuscripts at

http://www.hindawi.com
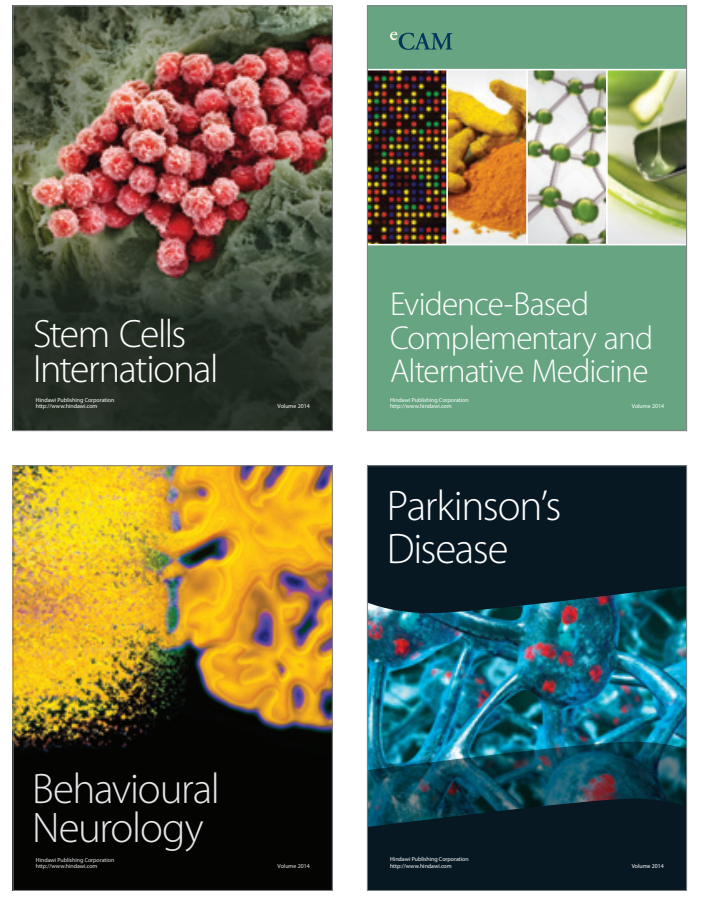
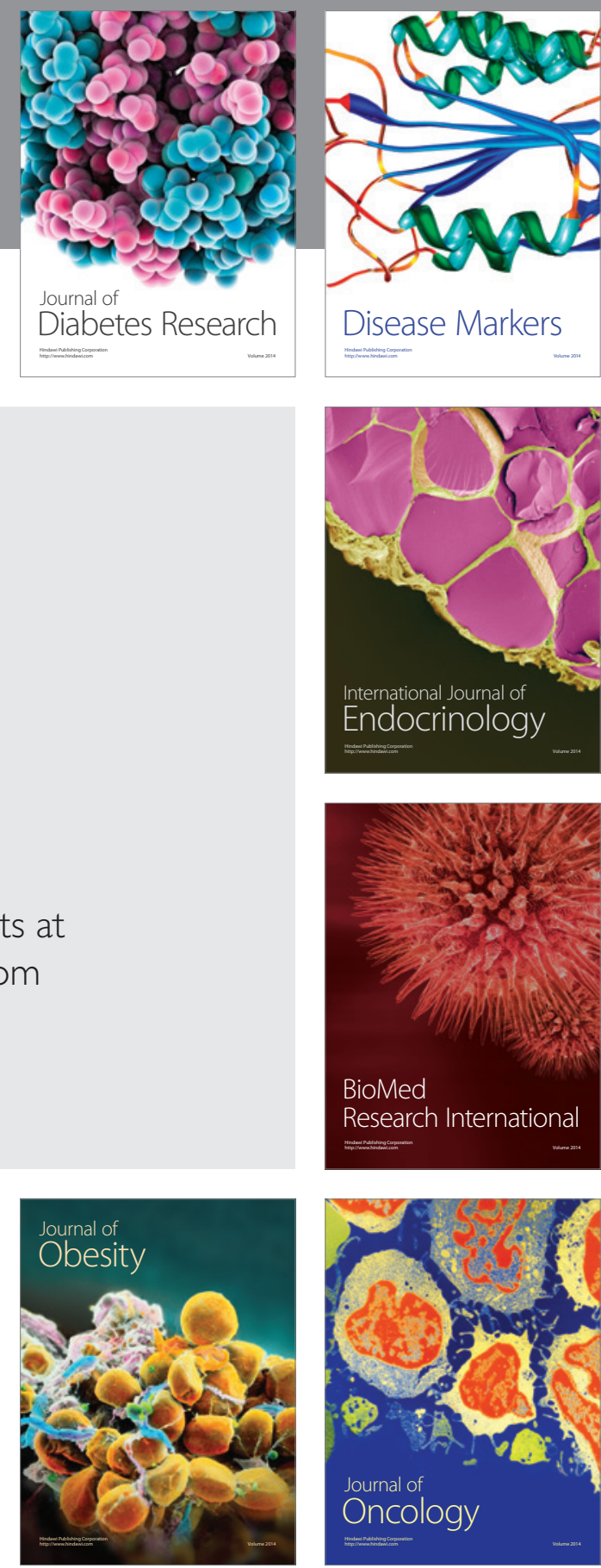

Disease Markers
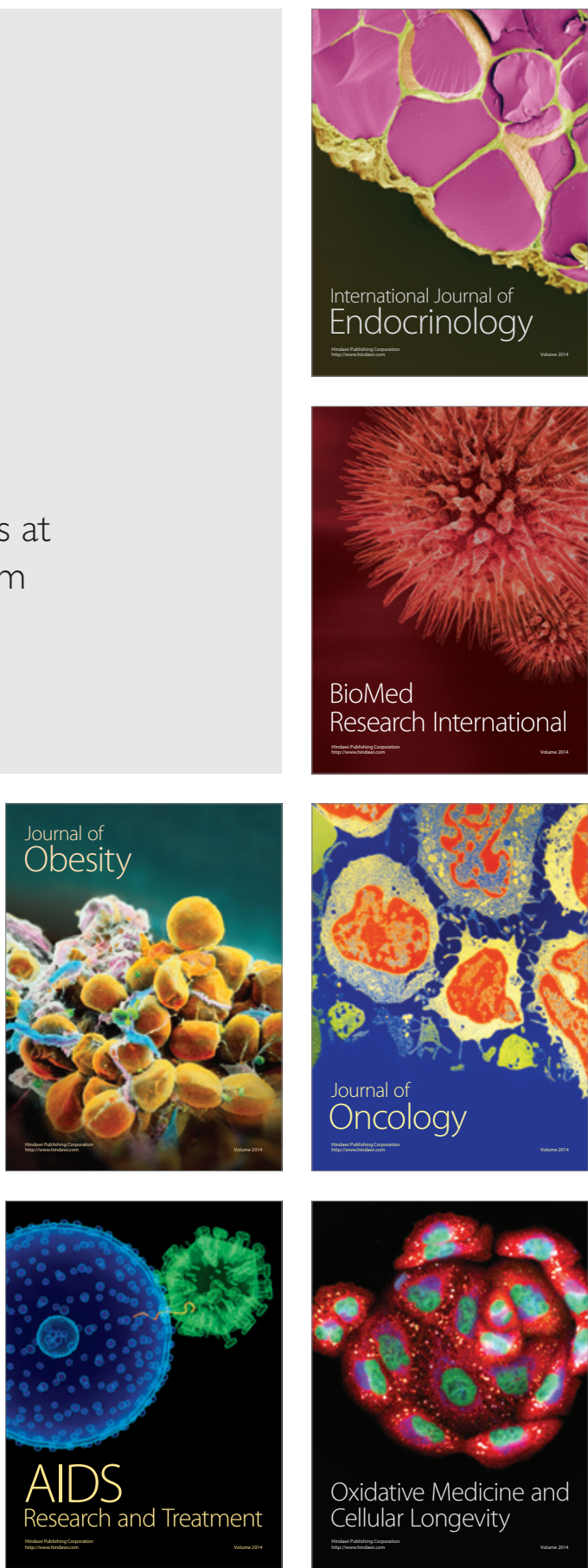